\title{
Use of Knowledge Base for Improving Equipment for Preparatory Works in Forest Areas (By Example of Increment Borer and Tree Caliper)
}

\author{
Shegelman I. R., Vasilev A. S., Sukhanov Y. V., Galaktionov O. N., Kuznetsov A. V., Anuchin A. \\ S., Shtykov A. S.
}

\begin{abstract}
The forest complex of the Russian Federation undergoes a transition from extensive model of harvesting and forestry to the intensive one. Such a transition requires a quality forest and technological preparation of forest areas for logging operations. The key basic material for such preparation is the assessment of qualitative and quantitative indicators of stands of forest resources of forest enterprises, which includes the assessment of stand age structure, growth course of different wood species, stand qualitative structure and a number of other inventory indicators. The need to enhance the quality of forest and technological preparation of forest areas necessitates the raise of requirements for inventory instruments. In this regards, over the last years there has been increased attention of researchers and developers to the elaboration of existing and development of new types of inventory instruments. Their development based on the fundamentally new patented technological and technical solutions which is the principal indicator of the level of these intellectual property objects. The authors develop the patentable objects of intellectual property on the basis of methodology of functional and technological analysis and synthesis of new technical solutions applying the built knowledge bases on improved or newly created objects of technology based on the expanded patent-information search. Considering the example of inventory instruments (increment borers and tree caliper), the effectiveness of knowledge base use with application of the functional and technological analysis as
\end{abstract}

Revised Manuscript Received on September 25, 2019

Shegelman I. R., Doctor of Technical Sciences, Professor, Cross-cutting technology and economic security, Petrozavodsk State University (PSU), 33, Lenina pr., 185910, Petrozavodsk, Republic of Karelia, Russia;

Vasilev A. S., Candidate of Technical Sciences, Associate Professor, Technologies and organizations of the forest complex, Petrozavodsk State University (PSU), 33, Lenina pr., 185910, Petrozavodsk, Republic of Karelia, Russia;

Sukhanov Y. V., Candidate of Technical Sciences, Associate Professor, Technologies and organizations of the forest complex, Petrozavodsk State University (PSU), 33, Lenina pr., 185910, Petrozavodsk, Republic of Karelia, Russia;

Galaktionov O. N., Doctor of Technical Sciences, Associate Professor, Technologies and organizations of the forest complex, Petrozavodsk State University (PSU), 33, Lenina pr., 185910, Petrozavodsk, Republic of Karelia, Russia;

Kuznetsov A. V., Doctor of Technical Sciences, Associate Professor, Technologies and organizations of the forest complex, Petrozavodsk State University (PSU), 33, Lenina pr., 185910, Petrozavodsk, Republic of Karelia, Russia;

Anuchin A. S, Graduate student, Technologies and organizations of the forest complex, Petrozavodsk State University (PSU), 33, Lenina pr., 185910, Petrozavodsk, Republic of Karelia, Russia;

Shtykov A. S., Department of Innovation and Production Activities Deputy Head of Department, Petrozavodsk State University (PSU), 33, Lenina pr., 185910, Petrozavodsk, Republic of Karelia, Russia. an instrument for establishment of new intellectual property was demonstrated.

Index Terms: intellectual property, forest area, timber harvesting, logging operations, patent, forest inventory.

\section{INTRODUCTION}

Forest and technological preparation of forest areas is one of the most important stages of logging operations that determines their further efficiency. The possibility of minimizing labor, financial and energy costs for logging significantly depends on the quality of these operations. Reliable information about the qualitative and quantitative indicators of forest stands intended to the felling is the key element of the built information knowledge base for tactical and strategic decision-making in the field of environmental management in forest and technological preparation of forest areas and in the subsequent stages of logging.

Modern methods of inventory provide such a reliable and up-to-date information knowledge base on forest resources with the assessment of a wide range of data on forest stands in the forest sector. Inventory technologies, devices, instruments and equipment are used at various stages of forestry operations, including forest management, forest inventory, forest allocation for exploitation, plot sampling, as well as researches (Artemiev et al., 1997; Bugaev et al., 2000; Vagin et al., 1978: Moshkalev et al., 1982; Nagimov et al., 2019; Sukhikh et al., 1974; Aleixo da Silva et al., 1994; West, 2009).

In view of the above, for the development inventory, industrial timber enterprises of various countries invent a variety of designs of inventory instruments of different types and brands. These include tree caliper, chains, logger tape, hypsometers of different types, forest or dip compass, increment borers, increment hammers, etc. (Anuchin, 1982; Kliuev, 2016; Martynov et al., 2008; Vagin et al., 1978; Bollandsås et al., 2007). The need to improve the quality of forest and technological preparation of forest areas, in turn, necessitates the increased requirements for these instruments. 
All this has determined the increased attention of scientists and developers to the elaboration of existing and development of new types of inventory instruments (Kliuev, 2013, 2014, 2016; Brooks et al., 2008; Case et al., 2008).

Their development based on the fundamentally new competitive technological and technical objects of intellectual property is the principal indicator of the level of these inventory instruments. Consequently, these objects should be protected by protection documents, i.e. be patented. Invention of patentable objects of intellectual property by the authors is based on the methodology of functional, structural and technological analysis and synthesis of new technological and technical solutions. The most important tool in this case is the knowledge bases building on existing/improving/newly created objects of technology on the basis of expanded patent information search.

The present work includes the building of knowledge base in the field of improvement of technologies, devices, instruments and equipment for forest preparation of forest areas for forest exploitation. Considering the example of increment borers and tree caliper, the effectiveness of knowledge base use with application of the functional, structural and technological analysis as an instrument for establishment of new objects of intellectual property was demonstrated.

\section{LiterATURE REVIEW}

When solving numerous issues of forestry and logging, including the forest raw material and technological preparation of forest areas, modern methods and data of forest inventory with the formation of reliable information about the qualitative and quantitative characteristics of forest stands intended to the felling are widely used. In this regard, researchers and developers are actively synthesizing advanced technological solutions aimed at invention of competitive devices, tools and equipment for forest inventory.

V. N. Sukachev Institute of Forest of the Siberian Division of the Russian Academy of Sciences (IL SO RAN) has defined and patented a method of determining the density of complex, mixed, and all-aged stands (Patent RU2531329). The method is based on conducting a comprehensive forest inventory of the stands in the field and processing of results of the stands inventory survey. In this method, a more accurate identification of stands density leads to accurate definitions of stand volume. Accordingly, the real productivity of stands, which is necessary in assessing the productivity of forest biogeocenosis types (forest types), is determined with high accuracy. It is important for forestry organization according to types of site conditions using the integrated inventory indicators. The purpose of the development of another method for determining density of complex, mixed, and all-aged stands by IL SO RAN (Patent RU2535725) is to obtain more accurate, universal and easy-to-use method for assessing the complex stands productivity.

Specialists of the Moscow State Forest University (MGUL) has developed and patented new method of forest stands inventory (Patent RU2183847). According to this method, the density of forest stands is defined as the ratio of the number of pixels allocated as a result of the inverse Fourier transform to their total number.

The method of forest inventory on drained lands (Patent RU2254708) includes allocation of plots homogeneous in soil conditions with separate determination of inventory indicators. The novelty of the method is that the plots with a width of $0.4-0.6$ between the canal routes are allocated along these routes, other plots are allocated in the middle parts between them.

Specialists of the Ural State Forest Engineering, in order to improve the accuracy of determining the trunk volume of growing trees and its simplification, has developed a new method of forest inventory (Patent RU2050114). Implementation of the method involves the selection of model trees. Using them, the values of a new form factor are determined. The trunk height is measured to the contact point of the line drawn from its top to the forming curve. Then, the trunk volume is determined by the equation derived by the author.

Mari State Technical University has patented a method of measuring growth rings on the trunk cut (Patent RU2237402). According to the method of tree trunk measurement widespread in forest inventory (Anuchin, 1982), measurement of diameter of a trunk and tree cut is performed by tree caliper, these measurements are made on a tree trunk/cut in two mutually perpendicular planes. A new method (Patent RU2236115) is proposed by Mari State Technical University to improve the accuracy of measuring the cut radius of a tree trunk. The novelty of the method lies in the fact that the lower part of the ring is turned upwards, then an axis is set in the center of the growth rings, on which a protractor and a millimeter ruler are put on. By ruler turning, radius of the growth rings, their groups and cut cross-section is determined. This University also obtained an invention for the method of analysis of tree trunk cuts (Patent RU2265841). This method allows assessing the model trees with wrongly stereometricly formed trunks.

The method of determining the dimensional technological parameters of tree trunks (Patent RU2557167) was patented by VGLTU. The method includes measuring the length and diameter of the trunks in the bark along the trunks length and in the butt-end cross sections. The novelty of the method consists in follows: 100 non-defective trees are examined, where their trunks length, the diameters in the bark in the butt-end, the diameters of the trunks in the bark, from the butt-end to the top, and the diameters of the trunks at half the trunk length are measured; the results of the measurements determine the relative lengths and the corresponding relative diameters of the trunks in the bark; the totality of obtained data determine the absolute size of tree trunks; taking into account the coefficients on the bark and the diameter of the trunk at breast height in the bark, the variable diameters of trunks without bark are determined, followed by the 
determination of the variable cross-sectional area of trunks without bark along the trunks length and volume of tree trunks without bark.

The above information was considered in a wide range of studies in the field of improving the methods of forest stands inventory aimed at improving the quality of inventory, the accuracy of the data obtained, reducing the complexity of the processes of forest resources studies. It is necessary to note the increased attention to the issues of remote sensing of vegetation cover (Bartalev et al., 2005; Lupian et al., 2011; Patent RU124788; Chasmer et al., 2006; Leeuwen et al., 2010; Naesset, 2004, 2007; Vastaranta et al., 2013, etc.). At the same time, a number of forest stand indicators can be assessed only through field studies in forest areas.

The analysis displayed the need to improve methods, devices, instruments and equipment for the stand inventory by in-situ measurement of the parameters of trees in forest area conditions. A number of authors rightly point out that currently many methods of natural inventory of plantings by methods of in-situ inventory of stands by measuring the trees parameters have been developed (Anuchin, 1982; Baginskiy, 2013; Tiurin, 1945). However, they do not highlight the need to improve these methods on the basis of modern science and technology. The authors consider it necessary to focus on the relevant researches (Almetov, 2001, Kliuev, 2013, 2014, 2016; Patent RU2633791; Patent RU2363149; Wulder et al., 2012; Williams et al., 2005; Luoma et al., 2017, etc.), indicating the need to improve the instruments used in forest inventory.

\section{MATERIALS AND METHODS}

Technologies and equipment for forest raw materials and technological preparation of forest areas for forest exploitation were chosen as the object of research. The purpose of the work is to build a knowledge base in the field of technology for forest raw materials and technological preparation of harvesting areas and prove the effectiveness of the use of knowledge base with application of the methodology of functional, structural and technological analysis for the formation of new patentable intellectual property.

The results of the collection and subsequent analysis of the findings of research and development made by domestic and foreign researchers, developers and inventors were used as material base. The collection of materials was based on the fact that the active search for methods of technical re-equipment of basic operations of the forest complex is actively conducted in many countries. When conducting patent search among the law enforcement documents registered in the territory of Russia, the information retrieval system of the Federal Institute for Industrial Property (FIPS) was used. Data on foreign inventions in the studied area were collected. The knowledge base of the Russian Science Citation Index and search engines were actively used to collect information.

According to the research methodology, the following tasks were addressed: a) building of a knowledge base in the field of technology and equipment for forest raw materials and technological preparation of harvesting areas; b) the allocation of specific objects of inventory equipment for the application of functional, structural and technological analysis. Among the inventory equipment, there are increment borers and tree calipers; c) in-depth analysis of the allocated inventory equipment with the identification of room for improvement; d) the synthesis of new patentable intellectual property objects.

When using the methodology of functional, structural and technological analysis, the object of technology was considered both in the process of its functioning and manufacture. This method involves structuring the collected information in relation to the examined object. After selecting the object of study (increment borers and tree calipers), for which improvement it was planned to find a new technical solution, a patent information search was conducted to identify similar designs (competitive analogues) or technologies, depending on the characteristics of the studied object. A thorough comprehensive study of the studied object was conducted and the closest analogues of increment borers and tree calipers were identified from a constructive, technological, operational view. Structural analysis contributes to the study of the structural component of the studied objects of technology. Technological analysis contributes to the study of the process of functioning of these objects of technology. Operational features were also taken into account in the functional analysis.

When implementing the methodology, the following stages of work were performed consistently, and sometimes in parallel: a) building of a creative team(s) under the leadership of a scientific leader who knows the methodologies of functional, structural and technological analysis and organization of collective solutions of inventive tasks. Experience has shown the need to include in the creative team the specialists in study area, professional inventors, specialists who masters the methods of patent information retrieval, and, if necessary, patent specialists; b) identification of the most promising areas for research aimed at creating technological and technical solutions that provide elementary or quantum leap in the development of modernized/replaceable technology objects; c) familiarization of creative team members with the methodologies of functional, structural and technological analysis and brainstorming: d) building of knowledge bases by advanced collection and analysis of scientific and technical information (a special place is occupied by patent search that requires special skills, knowledge and abilities); e) presentation of the knowledge base to the creative team members; f) analysis of the knowledge base and discussion on the state and trends in the development of technologies and equipment of the transformed/replaceable object of technology; g) clarification of the inventive task, if necessary, the knowledge base development; $h$ ) synthesis of ideas for new patentable solutions - intellectual property objects - using functional, structural and technological analysis and brainstorming; i) 
discussion and specifying of ideas by their structuring in the form of descriptive, technological, structural, economic models; j) registration of the most promising technical solutions in the form of applications for patents of inventions and utility models.

\section{RESULTS AND DISCUSSION}

Borers and tree calipers were selected as specific objects of inventory equipment for application of functional, structural and technological analysis among inventory equipment increment.

A method of measuring the thickness (diameter) of growing/fallen trees by tree caliper is known from the practice of Russian inventory. The traditional tree caliper usually consists of a graduated beam with two movable and fixed bars located at a right angle to it. They provide coverage of the diameter of a measured trunk. In addition to the traditional tree caliper, there were offered its other designs. For example, a tree caliper applied by All-Russian Research Institute for Silviculture and Mechanization of Forestry (VNIILM), has a movable bar mounted on a carriage with two ball bearings contacting with the side faces of the graduated beam, when moving. The beam is graduated as a double scale with divisions in millimeter and four millimeters.

Measurement of trees using traditional tree caliper is performed by two or three workers: first of them measures the trees, the second records the results of measurements in a special sheet, the third marks the measured trees (Baginskiy, 2013). It should be noted that the disadvantages of the traditional tree caliper (Zagreev et al., 1991) consist in the low productivity and inaccuracy of measurement of the diameter at the tree height, in the need for additional equipment (platform or ladder) when measuring diameters on a growing tree.

Currently, automatic and electronic tree calipers are known. They represented in the form of a traditional tree caliper with an electronic device with sensors. Its benefit is that the inventory and measurement of trees using electronic tree calipers can be performed by one person. The electronic device of the tree caliper is connected to the computer; the result is generated automatically. Such tree calipers are produced in Germany, Sweden and other countries.

Mari State Technical University has patented a method of measuring the diameter of a tree trunk (Patent RU2540557). The novelty of the method is that the measurement of the diameter and azimuth of this diameter is performed at specified intervals of azimuth, starting from the geodetic north; in order to measure the diameters at different heights from the earth's surface, one device is used.

This University has also patented a tree caliper, where on the measuring ruler there are fixed and movable legs in the form of try squares are fixed (Patent RU2242755). With use of such tree caliper, two tree diameters at three heights are measured.

The drawback of the well-known design of tree caliper (Zagreev et al., 1991) is that it does not provide for marking the measured trees, which can lead to the re-measurement of the same tree. To avoid repeated measurement, it is necessary to use an additional device that makes distinctive markers on trees.

The device for measuring the growing tree trunk diameter was patented by the Siberian State Technological University - SibSTU (Patent RU2226669). The novelty of the device is that it is equipped with a height pole and a cable with a pointer. The length of the pole is set equal to the height of the measurement. Such a device enables measuring the diameter of the tree trunk with the help of a hinged yoke contained therein at a height equal to the pole height. Later SibSTU has patented a device for measuring the diameter of a tree trunk (Patent RU143336), providing the possibility of measuring tree trunk and its diameter with larger distance between the legs of tree caliper at the height of measuring pole without increasing the overall dimensions of the device.

Another device invented by SibSTU (Patent RU135406) contains a plate with graduated scale, with movable rotatory and stationary legs fixed thereon. Its design eliminates the shortcomings of the known devices (Tesliuk, 1978; Patent RU2236115). The device increases the accuracy of measuring the tree trunk diameter. Its fixed leg consists of two pin-jointed elements, and the plate is equipped with a second graduated scale positioned parallel to the first scale. This makes it possible to increase the accuracy of measuring the trunks diameter, including those whose diameter exceeds the distance between the legs of tree caliper by spreading apart and fixing the legs of the tree caliper when measuring.

The unique design of tree caliper device serving to detect rot in tree trunks was patented by Mari State Technical University (Patent RU2203532). It is equipped with an ultrasonic device with sensors and tree caliper. The operating principle of the device is based on the relationship between the tree diameter, its wood density and the duration of the of ultrasonic waves propagation in wood and rot.

The Central Experimental Design Bureau of Forestry Engineering (Patent RU2189731) has patented a tree caliper that comprises a slider block with a movable bar and a compensator. In this case, the compensator of tree caliper is made as two plates, different in length, located on different sides of the ruler, the longer plate is equal to the length of the slider block.

Voronezh State Academy of Forestry Engineering (VGLTA) has patented an electronic tree caliper (Patent RU2363149). The fundamentally new features of the electronic tree caliper consist in that the slider block is made from non-magnetic material, the tree caliper is equipped with a Hall sensor, a signal conversion circuit, a display and a passive magnet for fixing the slider block on the ruler. In addition, the author proposed to produce the ruler of tree caliper from non-magnetic material and equip it with passive magnets.

Blue Eyes Intelligence Engineering \& Sciences Publication 
The authors had a good reason for choosing increment borer as a device of inventory equipment requiring significant modernization, along with tree caliper. The fact is that currently one of the main methods to assess the characteristics of a growing tree in the stand is the sampling of its specific part - core. The core is retrieved by special inventory device - the increment borer.

The core obtained as sample can be used to determine a number of parameters of a growing tree, including its age, increment, tree density (Almetov, 2001). With its use in forest inventory, it is also possible to assess the results of anthropogenic factors affecting the tree (fires, droughts, diseases, poor quality of forestry). By these samples it is possible to assess many properties of wood of the growing tree. When establishing the characteristics of the forest stand with the proper use of increment borers, it is important to obtain samples from growing trees, which then continue to grow (that is, there is no need for cutting model trees to obtain samples).

The Pressler increment borers, which allow obtaining cores with a diameter of 4-7 $\mathrm{mm}$, have been long used in the practice of forestry. However, in the operational practice the experts noted that the auger of these borers often damages both the core and the tree trunk when penetrating the growing tree. For a full analysis, it is advisable to use the borers for core extraction with a diameter of 6-10 $\mathrm{mm}$. There is a need for technology and means of extracting samples from the trunk, branches, stumps or roots with the least possible damage to the growing tree (Kliuev, 2013, 2014, 2016).

In the traditional and widely used version of the increment borer design, a handle is used for its rotation. In the design of the increment borer "Quad-B" (Brown, 2007), the borer handles were specially bent at an angle to its axis. This significantly expands the technological possibility of using the increment borer and allows its using in typically problematic places when sampling the tree butt-end part or sampling a low-crown tree with a large number of branches at the butt-end.

Within the framework of dissertation, Almetov (2001) has invented and patented the unique design of the increment borer for wood core extraction (Patent RU2163865). The borer is equipped with a feed mechanism in the form of an additional hollow body with an internal thread. This patented increment borer design reduces core damage and reduces the forces on the wood from the cutting part of the borer when removing cores with a diameter of more than $5 \mathrm{~mm}$. Previously, Almetov together with Mazurkin has developed and patented the design of the increment borer cutting part to extract wood core (Patent RU2158676). With its use in retrieving tree cores, there is observed reduced damage to the tree and core, the structure of the borer cutting part is significantly simplified. In addition, the process of wood fibers grinding is facilitated, and, consequently, the complexity of the process of borer penetration in the wood is reduced. The presence of undercuts and slots significantly reduces the friction forces when using the increment borer.

Volga State University of Technology (PovGTU) has patented the design of increment borer containing a hollow cylindrical body of the tool with an auger bit and a handle with a lock for rotating the tool (Patent RU2633791). Its characteristic feature is that the handle is designed as a gear box, where the driven gear is made with an open central part with a square hole for fixing the tool end opposite to the auger bit. The lock for fixing the tool is fixed to the driven gear housing. The gear box is made in the form of a pair of small-diameter driving gear and a larger-diameter cylindrical driven gear. The driving gear is inserted with a detachable connection at the end of the movable axis, located with the possibility of free rotation inside the fixed borer handle. A handle with a movable grip is rigidly fixed at the other end of the movable axis together with the driving gear. The design provides increase of functionality of wood core boring at the level of a tree root collar and reduction in the torque from the handle at increase of the torque on a cutting part of a borer when retrieving the core from hard-wood trees (an oak, a birch, etc.), operational flexibility also extends.

Functional, structural and technological analysis of knowledge base on the tree caliper design has shown that traditional and identified at the stage of knowledge base building technological and technical solutions in the field of improvement of the tree calipers and their operational processes have significant room for improvement. It should be noted that the invention of new technical solutions for the improvement of instruments on the basis of the production of electronic tree calipers, devices with tree calipers for assessing the defectiveness of growing trees and some others are successfully implemented by many universities, organizations and foreign companies. At the same time, the analysis showed that to date, when solving the problem of improving the design of tree calipers, the issues of expanding the tree caliper functionality have not been sufficiently resolved. That is why the authors focused on the development of new technical solutions for the design of tree calipers with the development and patenting of new intellectual property.

The analysis of the built knowledge base also displayed that the traditional increment borer design revealed during the knowledge base building has significant room for improvement. It consists in: a) usability inconvenience associated with simultaneous multidirectional forces in two mutually perpendicular planes (both in the direction of the borer penetration, and by its rotation with handle; along its axis with simultaneous rotation of the handle) applied to the increment borer penetrated in the wood; b) at the beginning of borer penetration it undergoes wobbling that reduces the quality of the retrieved core, due to its stair step structure (Almetov, 2001); c) limited ability to control the depth of the borer penetration in the wood (it is determined "by sight" or by sound, or by extractor attached to the tree trunk in the same plane with the borer). If the depth of the borer penetration does not reach the center of the tree trunk, the wood re-sampling is to be made. The borer penetration to the depth outside the center of the trunk causes unnecessary labor and time costs, as well as damage to the model tree; d) limited borer functionality due 
to the performance of only one operation - core retrieving. As a result of the functional, structural and technological analysis, the following avenues of improvement of increment borer by implementing the following technical solutions are identified: a) improving the usability of the increment borer by making structural changes in the mechanism of rotation (feed) of the borer to integrate the application of pressing and turning forces; b) creating conditions for the borer use in hard-to-reach areas of the tree, near its butt-end, branches, twigs, etc (in these cases, the full rotation of the borer is hindered by length of its handle); c) ensuring control over the depth of the borer penetration in the wood; improving the quality of the retrieved wood core; $d$ ) inventing a design that excludes the possibility of borer wobbling in the process of boring into the tree trunk; d) expanding the increment borer functionality.

During the functional and technological synthesis, the authors with the participation of G. V. Klyuev and V. M. Lukashevich developed new technological and technical solutions in the field of tree calipers and increment borers. The patented objects of intellectual property in the study area include the following devices, which are registered in name of Petrozavodsk State University.

Two patents were obtained on the design of tree calipers with enhanced functionality: "Calliper marker" (Patent RU168058) and "A drill for the removal of the core timber" (Patent RU157121). The former allows for combining technological operations of measuring the diameter of the tree trunk and its marking, the latter makes it possible to determine the diameter of the tree trunk and to retrieve the core from it. Let us consider them in more detail.

In the design of the multifunctional tree caliper - marker (Patent RU168058), the fixed bar is made with an internal cavity for the marking liquid. From the side contacting with the measured tree trunk, in the surface of the hollow leg there is an insert of a porous moisture-accumulating material, which is connected by channels to the leg cavity. The leg cavity has an additional channel designed to fill this cavity with a marking liquid, with a check valve. The check valve eliminates the spontaneous leakage of the marking liquid from the cavity of the hollow leg. The insert made from porous moisture-accumulating material is closed from the outside with perforated plate. With the use of a tree calipermarker, complexity of measuring the tree trunk and its marking is reduced by combining these operations. The marking of the tree trunk is performed automatically when measuring the diameter, and it also eliminates the human factor, when during the marking of the measured tree trunk, the operator may forget to mark it, which is possible when using a prototype, when it is required to make an additional action by pressing a button.

Design of the multifunctional tree caliper-borer (Patent RU157121) is not just largely improves the existing design of tree caliper (Anuchin, 1982, 28, Fig. 7b), but also significantly expands its functionality. The analysis displayed that the drawback of the known designs is the limited number of operations performed when using tree caliper. The existing designs enable to perform only one operation - measurement of tree trunk diameter during forest inventory. As a result, the researcher, during the inventory operation, in case of necessity to sample wood core along with the determination of the tree trunk diameter, needs to use several tools, which leads to an increased work complexity and reduced labor productivity. In the new patented design, the result is achieved by means of tree caliper body being made in the form of a hollow cylinder. In this case, at the end opposite to the one to which the fixed leg is attached, there is a conical auger bit, which has an outer screw thread. The proposed device of the borer allows for performing two operations, for which implementation two different tools were used previously - tree caliper and increment borer.

As a result of the functional, structural and technological analysis, the authors have also justified new technical solutions and obtained patents for a series of new designs of the following increment borers.

A number of solutions rectify the increment borer deficiencies (Almetov, 2001), when the borer jamming is possible during its penetration in the tree trunk. In addition, the borer entering the tree trunk may face a quite hard layer of wood, for example, when coring in the area of a large knot. In these cases, the operator exerts much forces on the handle, which can lead to overpressure. As a result, the hollow cylindrical body of the borer may break by its deformation or fracture. The technical result of the proposed device is to avoid the breakage of the cylindrical hollow body of increment borer due to applying excessive rotational forces on its handle, for example, in case of borer jamming in the tree trunk. In view of the above, the increment borer (Patent RU169677) comprises a cylindrical hollow body with an auger bit and a handle. The handle is connected to the cylindrical hollow body by means of a torque limiting safety clutch, which is in the form of two half-clutches, where a spring is installed on the driving half-clutch, transmitting the force for pressing the driving half-clutch to the driven one, and both half-clutches have holes for installing the retaining device.

The coring increment borer (Patent RU134478) can be used for coring the tree trunk at the hard-to-reach tree areas. These areas may be located close to tree roots, in swell-butted parts of tree, close to low-lying branches. In these areas, the full rotation of the borer handle protruding on both sides of the body is limited and even impossible. To eliminate this design shortcoming, the borer handle is connected to the body shank end through an adapter having a mounting seat corresponding to the size and shape of shank end of the hollow cylindrical body, while the adapter has a through hole perpendicular to its axis. A handle movable along this hole is installed therein. A thrust plate is installed at the end of the adapter, where a thrust bearing is installed between the thrust plate and the adapter. In case of coring close to the growing tree knot or root, when the handle complete rotation with its symmetrical arrangement relative to the adapter is impossible, the operator displaces it through hole of the 
adapter. The handle must then protrude only from one side of the adapter and is rotated to the maximum possible angle. Then the handle is moved again along the adapter through the hole in the position allowing to continue the rotational movement.

A borer-dynamometer (Patent RU157144) comprises a body with an auger bit at one end, a shank end at the other and a handle. Its distinctive feature is that dynamometer clamp is installed the shank end, providing transmission and measurement of the applied axial force, having a hollow cylindrical body with a longitudinal groove located along its geometric axis. Inside the hollow body there is a compression-spring-loaded rod connected to the pointer, which can be moved along the longitudinal groove. This borer has expanded functionality by providing the possibility of determination and control over the axial force applied to the body. This reduces the possibility of body deformation from the application of excessive pressure by borer pressing to the tree trunk due to timely pressure control.

Another borer-dynamometer (Patent RU149945) consists of a cylindrical hollow body with an auger bit and a handle. Its handle has a built-in dial dynamometer that includes a scale with moving pointer in the center. The mentioned device has enhanced functionality, so it can be used to determine the amount of force required for cutting the wood fibers. This allows for comparing the efficiency of auger bits of different designs depending on the density of wood. Due to the scale and pointer, it is possible to visually control the force pressure applied on the handle, which will prevent the application of excessive forces that can lead to breakage of the hollow cylindrical body and thereby reduce the probability of device breakage.

Another patented device is the coring increment borer (Patent RU134847), aimed at simplification of wood coring process and decrease of probability of its damage in the course of tree trunk coring that leads to simplification and increased accuracy of cored wood study. The borer handle is installed by a ratchet mechanism. During the wood coring, the handle is forcefully pushed and thus the device is tightly pressed to the tree trunk while rotated by the handle. As screw-threaded conical part penetrates the wood, the device is drawn in the wood that happens by itself due to screw thread on the cone surface. Due to the ratchet mechanism, it is enough to make the manual alternating movement holding the handle. There is no need for constant handle re-gripping, which is necessary when coring with a device with rigid fastening of handle to the body.

"The guide device for the auger age" (Patent RU135575), consists of a cylindrical hollow body with a tree-trunk fastening mechanism, installed on a supporting platform, and a coiled mounting strap. The novelty of the device is that the coil is rigidly connected to the wormwheel, interacting with the worm, rigidly connected to the handle. The device makes the process of its fixing to a tree trunk much more convenient, increases the reliability of fixation. Its use helps avoid borer wobbling during its entering into the tree trunk, eliminates damage to the core and reduces the degree of damage to the tree trunk. Another patented device is "A device for guiding the auger" (Patent RU142445). The technical result of the proposed solution is to increase the convenience of the borer fixing process, reducing the time spent, reducing the probability of core damage during its removal from the tree trunk by eliminating the possibility borer wobbling. "The guide device for the auger" (Patent RU134478) also helps to avoid the borer wobbling during coring.

Among patented devices, there is an increment borer for wood investigation (Patent RU141050). This borer can be used for taking cylindrical wood samples, and even from standing trees, in wood certification of the growing and fallen trees, in study of physical and mechanical properties of wood. It can also be used in identification its fungi damage degree, in determining the state of the wood elements of various building structures, in the study of the processes of dehydration and impregnation of wood to determine the dehydration degree of its various layers and identify the depth of penetration of the impregnating liquid. Its distinctive features are as follows. It has longitudinal mortises on the outer surface of the hollow body; the same number of tenons are made on the inner surface of the mounting seat of the handle that is adjacent to the surface of the hollow body. As it has the mortises, it is possible to place the handle on the hollow body at operator-oriented distance, with respect to length of operator's hands, as well as to move the handle to the auger bit as close as possible in coring the hardwood or in case of borer jamming. The twisting stress of the hollow cylindrical body of the borer is reduced, which significantly reduces the probability of breakages of the borer body. The placement of the handle near the auger bit minimizes the borer wobbling, which occurs at the initial boring moment, until the auger bit enters the wood of the studied tree trunk to a depth sufficient for self-drawing of the hollow body in the wood. This reduces the wood core damage, both at the initial moment of boring, and in the process of its retrieval from the tree trunk.

Given the similarity in functionality of increment borer and increment hammers, the authors patented two versions of the increment hammer design. One of the increment hammers (Patent RU142442) at the end of the handle has a load and a detachable hollow tip for core sampling. The load is made with a through longitudinal groove for pusher passage serving for core extraction from the core sampling mechanism. The load moves along the longitudinal axis of the tip, whereon the spring-loaded anvil is installed relative to the load. The advantage of this device is in reducing the blunting intensity and the probability of breakage of the detachable hollow tip, even when working with hardwood and in case of hammering the knots area, where the wood is of increased hardness, therefore, it increases the service life of the hollow tip of the increment hammer. In another design of the increment hammer (Patent RU157061), a hollow rod is equipped with a percussion mechanism located on the side opposite to the sharp tip, and spring-loaded relative to the load serving as an anvil. The advantage of this device consists in that it reduces the

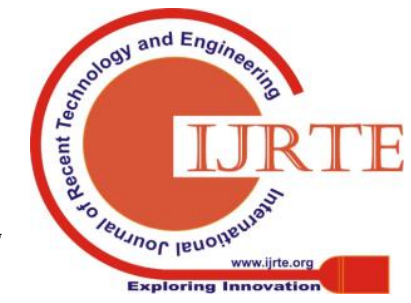


blunting intensity and breakage of the core sampling mechanism, as well as in its applicability when working with hardwood.

\section{Conclusions}

Forest raw materials and technological preparation of forest areas is one of the most important stages of logging operations that determines their further efficiency. The key element of the information knowledge base at this and subsequent stages of logging is reliable information about the qualitative and quantitative indicators of forest stands intended to the felling. To obtain such information, a variety of inventory instruments of various types are used. Among them are tree caliper, chains, logger tape, hypsometers of different types, forest or dip compass, increment borers, etc. The need to improve the quality of forest resources and technological preparation of forest areas necessitates the increased requirements for these instruments. All this has determined the increased attention of scientists and developers to the elaboration of existing and development of new types of inventory instruments. Their development is based on the fundamentally new competitive technological and technical objects of intellectual property is the principal indicator of the level of these inventory instruments. In view of the above, the researchers and developers are actively synthesizing the promising technological ideas in the field of invention of competitive devices and instruments for forest inventory. The analysis of the built knowledge base displayed that the traditional design of tree caliper and increment borer has significant room for improvement.

Considering the example of increment borers and tree caliper, the effectiveness of knowledge base use with application of the functional and technological analysis as an instrument for establishment of new intellectual property was demonstrated. The number of fundamentally new technical solutions were developed and patented by the authors with applying this methodology. Two patents were obtained for the design of multifunctional tree calipers, nine patents for the design of increment borers and two patent for the design of increment hammer.

\section{REFERENCES}

1. Almetov, A. N. (2001). Russian Patent no. 2163865 "Borer for extraction of wood core."

2. Almetov, A. N. \& Mazurkin, P. M. (2000). Russian Patent no. 2158676 "Cutting part of drill for wood core extraction."

3. Aleixo da Silva, J. A., Borders B. E \& Brister G. H. (1994). Estimating tree volume using a new form factor. Commonwealth Forestry Review, 73, 14-17.

4. Almetov, A. N. (2001). Improvement of the design of the borer for wood core extraction from growing trees of various species (Doctoral dissertation). Yoshkar-Ola, p. 174. assessment of tree height measurements obtained using airborne lidar and conventional field methods. Canadian Journal of Remote Sensing, 32, 355-366.

6. Anuchin, N. P. (1982). Forest inventory (5th ed.). Moscow: Lesnaya Promyshlennost.

7. Artemiev, O. S. (2013). Russian Patent no. 135406 “A device for measuring the diameter of the tree trunk."

8. Artemiev, O. S. \& Artemiev, I. S. (1997). Methods of growing tree parameters assessing with machine vision system. In Forest Inventory and Forest Management (pp. 133-135). Krosnoyarsk: KGTA.
5. Andersen, H. E., Reutebuch, S. E. \& McGaughey, R. J. (2006). A rigorous

9. Artemiev, O. S. \& Naidenko, E. A. (2014). Russian Patent no. 143336 "Device for remote measurement of a growing tree trunk diameter."

10. Artemiev, O. S. \& Zaichenko, L. P. (2004). Russian Patent no. 2226669 "Device measuring diameter of trunk of growing tree."

11. Baginskiy, V. F. (2013). Forest inventory. Gomel: GGU im. F. Skoriny.

12. Bartalev, S. A., Lupian, E. A., Neishtadt, I. A. \& Savin, I. Yu. (2005). Remote assessment of agricultural land parameters through satellite data of MODIS spectroradiometer. Sovremennye Problemy Distantsionnogo Zondirovaniya Zemli Iz Kosmosa, 2(2), 228-236.

13. Bollandsås, O. M \&. Næsset, E. (2007). Estimating percentile-based diameter distributions in unevensized Norway spruce stands using airborne laser scanner data. Scandinavian Journal of Forest Research, 22, 33-47.

14. Brooks, J. R., Jiang, L. \& Ozçelik, R. (2008). Compatible stem volume and taper equations for Brutian pine, Cedar of Lebanon and Cilicica fir in Turkey. Forest Ecology and Management, 256, 147-151.

15. Brown, P. M. (2007). A modified increment borer handle for coring in locations with obstructions. Tree-Ring Research, 63(1), 61-62.

16. Bugaev, V. A. \& Serikov, M. T. (2000). Recreational forest management In Forest Inventory and Forest Management (pp. 143-149). Krosnoyarsk: SibGTU.

17. Case, B. S. \& Hall, R. J. (2008) Assessing prediction errors of generalized tree biomass and volume equations for the boreal forest region of west-central Canada. Canadian Journal of Forest Research, 38, 878-889.

18. Chasmer, L., Hopkinson, C. \& Treitz, P. (2006). Investigating laser pulse penetration through a conifer canopy by integrating airborne and terrestrial lidar. Canadian Journal of Remote Sensing, 32, 116-125.

19. Davydov, V. F., Illarionov, G. P., Shalaev, V. S., Komarov, E. G. \& Mukhin, A. S. (2002). Russian Patent no. 2183847 "Procedure of plantation evaluation."

20. Kasianov, A. E. \& Kharin, O. A. (2005). Russian Patent no. 2254708 "Method of forest assessment on drainage lands."

21. Kazakov, V. I., Galanov, V. N., Beglova, G. N., Berezin, A. S. \& Anisimova, G. V. (2002). Russian Patent no. 2189731 "Tree measuring fork."

22. Kliuev, G. V. (2013). Research in the field of increment borers improvement. Inzhenerny Vestnik Dona, 4(27), 45.

23. Kliuev, G. V. (2014). Methodic principles of justification of promising equipment for forest inventory. Inzhenerny Vestnik Dona, 1(28), 49.

24. Kliuev, G. V. (2016). Inventory instrument as a method of rational forest utilization. Inzhenerny Vestnik Dona, 3(42), 48.

25. Kliuev, G. V., Shegelman, I. R. \& Vasilev, A. S. (2015a). Russian Patent no. 157061 "Hammer incremental."

26. Kliuev, G. V., Shegelman, I. R. \& Vasilev, A. S. (2015b). Russian Patent no. 157144 "A drill with holder, dynamometer."

27. Leeuwen, M. \& Nieuwenhuis, M. (2010). Retreival of forest structural parameters using LiDAR remote sensing. European Journal of Forest Research, 129, 749-770.

28. Lukashevich, V. M., Shegelman, I. R. \& Vasilev, A. S. (2013). Russian Patent no. 134847 "Borer age for extracting a core of wood."

29. Luoma V., Saarinen N., Wulder M., White J., Vastaranta M., Holopainen M. \& Hyyppä J. (2017). Assessing precision in conventional field measurements of individual tree attributes. Forests, 8, 38. Retrieved from: https://www.mdpi.com/1999-4907/8/2/38/htm

30. Lupian, E. A., Savin, I. Yu., Bartalev, S. A., Tolpin, V. A., Balashov, I. V. \& Plotnikov, D. E. (2011). "VEGA" satellite service of vegetation status monitoring. Sovremennye Problemy Distantsionnogo Zondirovaniya Zemli Iz Kosmosa, 8(1), 190-198.

31. Martynov, A. N., Melnikov, E. S., Koviazin, V. F., Anikin, A. S., Minaev, V. N. \& Beliaeva, N. V. (2008). The fundamentals of forest management and forest inventory. St. Petersburg: Lan.

32. Mazurkin, P. M. \& Kudriavtseva, A. E. (2015). Russian Patent no. 2540557 "Method to measure diameter of tree trunk and device for its realisation."

33. Mazurkin, P. M. \& Meteleeva, O. A. (2004). Russian Patent no. 2237402 "Method for measurement of annular rings on tree trunk cut."

34. Mazurkin, P. M., Sadovin, D. V. \& Meteleeva, O. A. (2005). Russian Patent no. 2265841 "Method for analyzing of tree trunk saw cut."

35. Mazurkin, P. M., Sadovin, D. V. \& Pirogova, E. S. (2004). Russian Patent no. 2236115 "Method for measuring radius of tree trunk saw cut."

36. Mazurkin, P. M. \& Tishin, D. V. (2017). Russian Patent no. 2633791 "Drill for wood core recovery."

37. Moshkalev, A. G., Knize, A. A., Ksenofontov, N. I. \& Ulanov, N. S. (1982). Stand commodity pattern inventory. Moscow: Lesnaya Promyshlennost.

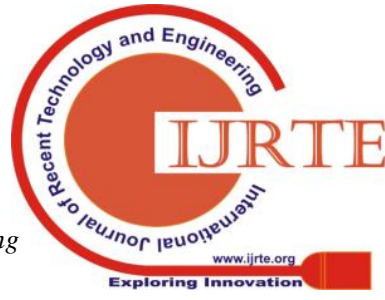


38. Næsset, E. (2004). Practical large-scale forest stand inventory using a small-footprint airborne scanning laser. Scandinavian Journal of Forest Research, 19, 164-179.

39. Næsset, E. (2007). Airborne laser scanning as a method in operational forest inventory: status of accuracy assessments accomplished in Scandinavia. Scandinavian Journal of Forest Research, 22, 433-442.

40. Nagimov, Z. Ya., Shevelina, I. V. \& Korostelev, I. F. (2019). Devices, instruments and equipment for forest inventory. Ekaterinburg: UGLTU.

41. Petrovskiy, V. S. (2015). Russian Patent no. 2557167 "Method of determining dimensional technological parameters of tree trunks."

42. Petrovskiy, V. S., Filipov, M. V. \& Murzinov, Yu. V. (2009). Russian Patent no. 2363149 "Electronic forest tree calipper."

43. Pogorelov, A. V., Steblovskiy, A. S., Kuznetsov, K. V. (2012). Russian Patent no. 124788 "Geographic information system of land monitoring."

44. Shavnin, A. G., Shavnin, V. A., Shavnin, S. A., Zvezdin, V. K. \& Kuznetsov, V. P. (1995). Russian Patent no. 2050114 "Method for assessment of volumes of growing tree trunks."

45. Shegelman, I. R., Lukashevich, V. M., Vasilev, A. S. \& Sukhanov, Yu. V. (2013). Russian Patent no. 135575 "The guide device for the auger age."

46. Shegelman, I. R., Sukhanov, Yu. V., Vasilev, A. S. \& Lukashevich, V. M. (2014). Russian Patent no. 142445 "A device for guiding the auger."

47. Shegelman, I. R., Vasilev, A. S. \& Kliuev, G. V. (2014a). Russian Patent no. 141050 "A drill for wood research."

48. Shegelman, I. R., Vasilev, A. S. \& Kliuev, G. V. (2014b). Russian Patent no. 142442 "Hammer incremental."

49. Sukhikh, V. I., Sidorenko, V. V. \& Borovikov, N. Z. (1974). Modern forest management and forest inventory. Pushkino: VNIShSh.

50. Tesliuk, N. K. (1978). Measurement inventory methods. Moscow: Lesnaya Promyshlennost

51. Tiurin, A. V. (1945). Forest inventory. Moscow: Goslesbumizdat.

52. Toropov, A. S., Anisimov, S. E., Volkova, L. P., Zhidkova, E. V. \& Kondakov, I. A. (2004). Russian Patent no. 2242755 "Measuring fork."

53. Vagin, A. V., Murakhtanov, E. S., Ushakov, A. I. \& Kharin, O. A. (1978). Forest Inventory and Forest Management. Moscow: Lesnaya Promyshlennost.

54. Vasilev, A. S. \& Shegelman, I. R. (2017). Russian Patent no. 169677 "Borer age."

55. Vasilev, A. S., Shegelman, I. R. \& Kliuev, G. V. (2015). Russian Patent no. 149945 "Borer-dynamometer."

56. Vasilev, A. S., Shegelman, I. R. \& Lukashevich, V. M. (2013). Russian Patent no. 134478 "The guide device for the auger."

57. Vasilev, A. S., Shegelman, I. R., Lukashevich, V. M. \& Sukhanov, Yu. V. (2015). Russian Patent no. 157121 "A drill for the removal of the core timber."

58. Vasilev, A. S., Shegelman, I. R., Lukashevich, V. M. \& Sukhanov, Yu. V. (2017). Russian Patent no. 168058 "Calliper marker."

59. Vasilev, A. S., Shegelman, I. R., Sukhanov, Yu. V., \& Lukashevich, V. M. (2015). Russian Patent no. 157145 "Calliper-borer."

60. Vastaranta, M., Wulder, M., White, J., Pekkarinen, A., Tuominen, S., Ginzler, C., ... Hyyppä, H. (2013). Airborne laser scanning and digital stereo imagery measures of forest structure: Comparative results and implications to forest mapping and inventory update. Canadian Journal of Remote Sensing, 39, 382-395.

61. West, P. W. (2009). Tree and Forest Measurement. Retrieved from: http://www2.ca.uky.edu/Forestry/FOR250/Tree\%20and\%20Forest $\% 20$ Measurement\%20book.pdf

62. Williams, R. J., Zerihun, A., Montagu, K. D., Hoffmann, M., Hutley, L. B. \& Chen, X. (2005). Allometry for estimating aboveground tree biomass in tropical and subtropical eucalypt woodlands: towards general predictive equations. Australian Journal of Botany, 53, 607-619.

63. Wulder, M. A., White, J. C., Nelson, R. F., Næsset, E., Ørka, H. O., Coops, N. C., ... Gobakken, T. (2012). Lidar sampling for large-area forest characterization: A review. Remote sensing of Environment, 121 196-209.

64. Zagreev, V. V., Gusev, N. N., Moshkalev, A. G. \& Selimov, Sh. A. (1991). Forest Inventory and Forest Management. Moscow: Ekologiya.

65. Zakamenskiy, V. A. \& Zakamenskiy, S. V. (2003). Russian Patent no. 2203532 "Apparatus for detecting rot in tree trunks."

66. Ziganshin, R. A. (2014a). Russian Patent no. 2531329 "Method of determining completeness of multi-storeyed, mixed, and uneven-aged timber stands."

67. Ziganshin, R. A. (2014b). Russian Patent no. 2535725 "Method of site class determination of complex, mixed, uneven-aged plantations."

\section{AUTHORS PROFILE}

Shegelman I. R., Doctor of Technical Sciences, Professor, Cross-cutting technology and economic security, Petrozavodsk State University (PSU), 33, Lenina pr., 185910, Petrozavodsk, Republic of Karelia, Russia;

Vasilev A. S., Candidate of Technical Sciences, Associate Professor, Technologies and organizations of the forest complex, Petrozavodsk State University (PSU), 33, Lenina pr., 185910, Petrozavodsk, Republic of Karelia, Russia;

Sukhanov Y. V., Candidate of Technical Sciences, Associate Professor, Technologies and organizations of the forest complex, Petrozavodsk State University (PSU), 33, Lenina pr., 185910, Petrozavodsk, Republic of Karelia, Russia;

Galaktionov O. N., Doctor of Technical Sciences, Associate Professor, Technologies and organizations of the forest complex, Petrozavodsk State University (PSU), 33, Lenina pr., 185910, Petrozavodsk, Republic of Karelia, Russia;

Kuznetsov A. V., Doctor of Technical Sciences, Associate Professor, Technologies and organizations of the forest complex, Petrozavodsk State University (PSU), 33, Lenina pr., 185910, Petrozavodsk, Republic of Karelia, Russia;

Anuchin A. S, Graduate student, Technologies and organizations of the forest complex, Petrozavodsk State University (PSU), 33, Lenina pr., 185910, Petrozavodsk, Republic of Karelia, Russia;

Shtykov A. S., Department of Innovation and Production Activities Deputy Head of Department, Petrozavodsk State University (PSU), 33, Lenina pr., 185910, Petrozavodsk, Republic of Karelia, Russia. 